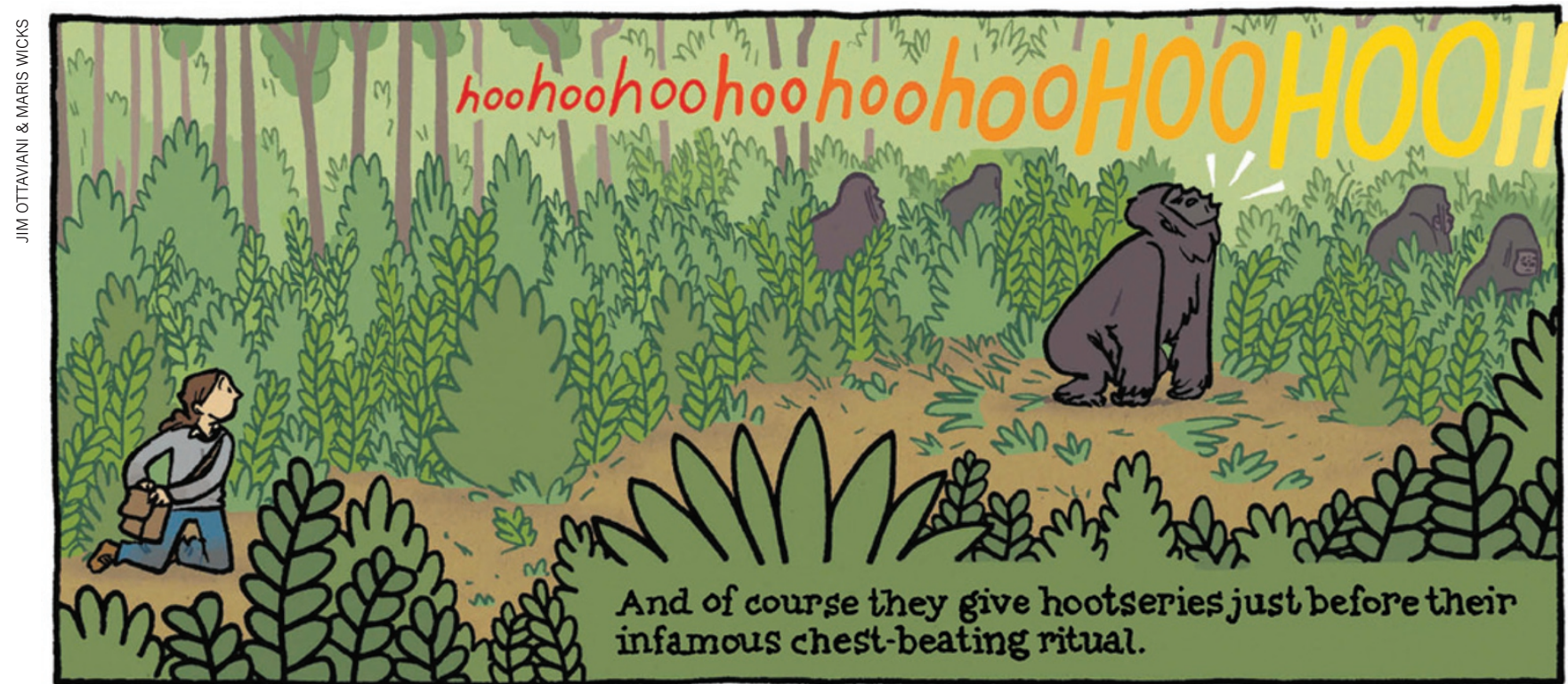

Dian Fossey viewing mountain gorillas in Primates.

ETHOLOGY

\title{
Primatological derring-do
}

\section{Kelly Stewart revels in a graphic biography that follows the human and scientific stories of three iconic primate researchers.}

A s enthralling careers go, those of trailblazing primatologists Jane Goodall, Biruté Galdikas and the late Dian Fossey take some beating. Now the personal and scientific stories of these pioneers of research on, respectively, wild chimpanzees, orangutans and gorillas feature in Primates, an engaging graphic biography by Jim Ottaviani and illustrator Maris Wicks. Unifying the three intimate firstperson narratives is the figure of renowned palaeontologist Louis Leakey, who helped to launch all three researchers' careers.

Ottaviani clearly carried out extensive research on published material by and about the trio of researchers, including diaries and letters. For a book that takes well under an hour to read and aims to engage teens, Primates offers a remarkable amount of information on many different levels. The life stories may be rendered as cartoons, but the characters come across as multi-dimensional. And there is plenty of human interest, from Fossey's uncompromising ferocity and mercurial personality to Galdikas's painful choice between returning to Canada with her husband and young son or remaining in Indonesia to continue her work with orangutans.

How true to life is it? As someone familiar with all three stories - especially that of Fossey, with whom I studied gorillas in Rwanda - I'd say it's an accurate rendition.
We learn about the logistics of fieldwork, which involves no shortage of discomforts to satisfy the gruesome fascination of young readers - days of being rained on, isolation, exhaustion and illness. Galdikas's story, set in the leech-infested Indonesian forest, is especially rich in the 'ick factor.' The characters cut trails, sift through dung for food remnants, spend months living alongside and observing their subjects, present their findings at a conference, suffer academic insecurity and social awkwardness, and struggle to balance anthropomorphism and objectivity.

Making it all worthwhile is the fascinating allure of living in the wild and becoming immersed in the lives of members of another species. Triumph also comes with discoveries, such as Goodall making the first observation of chimpanzees using tools. And of course, Ottaviani describes the inevitable fight to conserve the apes and their habitats, which eventually becomes the crusade of all three scientists.

The narrative occasionally suffers from a

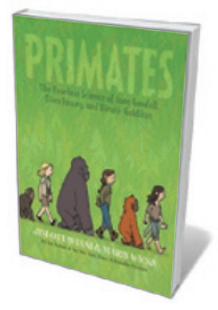

Primates: The Fearless Science of Jane Goodall, Dian Fossey, and Biruté Galdikas JIM OTTAVIANI AND MARIS WICKS First Second: 2013 144 pp. $\$ 19.99$ confusing shift in storyline or viewpoint, but is generally pithy and fast-paced. Although Wicks's artwork does not dazzle, it gets the point across, making ample use of expressions of comic exaggeration such as bugeyed surprise. She also applies comic touches that convey the vitality of forests and their denizens, with ape vocalizations that change colour and burst out of the cartoon frame. Many illustrations are clearly modelled on specific photographs from early National Geographic articles.

The best thing about Primates is that Leakey and the primatologists essentially become action heroes. They are unconventional but undaunted, persevering against the odds. They make sacrifices, lead daring lives, uncover mysteries and fight for the good; science and scientists are portrayed as cool and exciting.

This book won't teach kids much about the great apes, but that isn't its point. If it inspires young readers to explore the reading list provided at the end, and perhaps become scientists or conservationists, then - as one might say at the end of any action comic 'mission accomplished'.

Kelly Stewart is a research associate in the Department of Anthropology, University of California, Davis. She is co-author of Gorilla Society with Sandy Harcourt. e-mail:kjstewart30@gmail.com 